\title{
DEL RONDÓN A LA FRITANGA: REFERENTES CULINARIOS EN LA POESÍA DE NICARAGUA
}

\author{
Carlos Manuel Villalobos
}

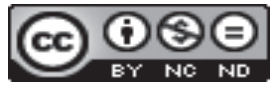

Doi: https://doi.org/10.15517/rfl.v44i2.34672

URL: https://revistas.ucr.ac.cr/index.php/filyling 



\title{
DEL RONDÓN A LA FRITANGA: REFERENTES CULINARIOS EN LA POESÍA DE NICARAGUA
}

\author{
FROM THE RONDON TO THE FRITANGA: CULINARY \\ REFERENCES IN THE POETRY OF NICARAGUA
}

\section{Carlos Manuel Villalobos}

\begin{abstract}
RESUMEN
Este artículo estudia el tema de la cocina nicaragüense como marca recurrente en la producción lírica de este país. Aunque hay algunas alusiones a este tema en el contexto de la poesía modernista, la mayoría de referencias al menú nicaragüense responden a una etapa reciente, que coincide con la popularización de este género, luego del triunfo de la Revolución Sandinista en 1979. Entre los textos que se consideran para este estudio destaca el poema "Menú nica" de Luis Rocha, publicado en 1996 en su libro La vida consciente, así como textos de Carola Brantone, Esthela Calderón, Blanca Castellón, Edgar Escobar, Róger Fisher y Carlos Perezalonso, entre otros autores. Uno de los descubrimientos relevantes de este trabajo es la constatación de que en la poesía caribeña nicaragüense la cocina es un tema prioritario, sobre todo como estrategia para representar los valores de la identidad regional. Gracias a este referente culinario en la poesía es posible determinar cómo se constituyen los códigos sintagmáticos y semióticos de la mesa nicaragüense.

Palabras clave: Poesía, literatura nicaragüense, cocina nicaragüense, discurso culinario, semiología de la comida.
\end{abstract}

\begin{abstract}
This article studies the Nicaraguan cuisine as a recurring brand in the lyrical production of this country. Although there are some allusions to this issue in the context of modernist poetry, most references to the Nicaraguan menu are a recent stage, coinciding with the popularization of this genre, after the triumph of the Sandinista Revolution in 1979. Are considered for this study highlights the poem "Menu nica" by Luis Rocha, published in 1996 in his book La vida consciente, as well as texts by Carola Brantone, Esthela Calderón, Blanca Castellón, Edgar Escobar, Roger Fisher and Carlos Perezalonso, among other authors. One of the relevant discoveries of this work is the realization that in Nicaraguan Caribbean poetry, cooking is a priority theme, especially as a strategy to represent the values of regional identity. Thanks to this culinary reference in poetry, it is possible to determine how the syntagmatic and semiotic codes of the Nicaraguan table are constituted.
\end{abstract}

Key words: Poetry, Nicaraguan literature, Nicaraguan cuisine, culinary speech, food semiology.

Dr. Carlos Manuel Villalobos. Universidad de Costa Rica. Profesor de la Escuela de Filología, Lingüística y Literatura. Costa Rica.

Correo electrónico: carlos.villalobos@ucr.ac.cr

Recepción: 14- 02- 2017

Aceptación: 02- 09- 2017 


\section{Introducción}

En 1974, el poeta argentino Armando Tejada Gómez ganó el Premio Casa de las Américas con un poemario titulado Canto popular de las comidas. Más allá del referente folclórico, este texto teje un amplio diálogo con la dinámica cultural latinoamericana. El tema de la comida funciona aquí como un anclaje estratégico que permite servir, en la mesa del consumo y la historia cultural, una amplia red de significados. Este poemario mostraba que lo gastronómico forma parte del tejido referencial de la llamada poesía que procura dar cuenta de lo propio como forma de resistencia política, frente a los códigos culinarios impuestos por el modelo del consumo masivo trasnacional. Esta misma idea, como ya veremos, ha sido abordada por diversos poetas nicaragüenses, donde lo culinario funciona como bandera de autonomía en el marco de los discursos de las identidades nacionales.

Este trabajo explora la presencia del referente gastronómico en la poesía nicaragüense de finales del siglo XX e inicios del XXI. Para ello se han escogido textos de autores que incluyen el tema culinario como referente poético. Entre los autores que abordan esta materia popular están Luis Rocha, Carola Brantone, Esthela Calderón, Blanca Castellón, Edgar Escobar, Róger Fisher y Carlos Perezalonso, entre otros.

El análisis de estos textos se hace desde una perspectiva semiótica, para ello se analizan algunos campos nocionales tales como lo folclórico, la resistencia cultural, el cliché erótico y lo mítico fundacional como arquetipo culinario. Para analizar esta polisemia, se consideran algunas fundamentaciones teóricas del semiólogo Roland Barthes. De acuerdo con este estudioso francés, la comida puede ser analizada como un sistema de significación, pues

\footnotetext{
Al comprar un alimento, al consumirlo y al darlo a consumir, el hombre moderno no manipula un simple objeto de una manera puramente transitiva; este alimento resume y transmite una situación, constituye una información, es significativo; esto quiere decir que no es simplemente el indicio de un conjunto de motivaciones más o menos conscientes, sino que es un verdadero signo, esto es, unidad funcional de una estructura comunicativa. No sólo hablo aquí de los elementos más aparentes de la comida, ligados a los ritos de hospitalidad, sino que toda la comida sirve de signo entre los participantes de una población dada (Barthes, 2006, p. 215).
}

En el caso de Nicaragua, lo culinario y los rituales de su consumo son ciertamente un importante referente en la identidad cultural. Basta una observación in situ para apreciar el popular fenómeno de las llamada fritangas o puestos casi improvisados de comida a la orilla de las calles en cada barrio. En estas ventas, los platos que se sirven tienen repollo rayado con tomate, chile congo, carne asada, cerdo adobado, plátano maduro, frijoles rojos, tajadas de plátano verde y pescado, entre otros ingredientes. En algunos puestos es posible encontrar también nacatamales, pinto, indio viejo, vaho, vigorón, como parte de la variedad tradicional. Este tipo de comercio, casi siempre informal, les permite a algunas familias generar recursos de sobrevivencia, mientras los clientes encuentran una opción accesible al bolsillo. Pero más allá de lo económico, las fritangas permiten mantener intacto el menú típico y, de este modo, enfrentar el consumo masivo de la llamada comida chatarra de las ofertas comerciales trasnacionales.

En la semiosis culinaria de estos recetarios es posible encontrar huellas históricas que muestran la herencia multiétnica. En una investigación sobre la tradición cultural de los mayangnas, una comunidad indígena nicaragüense, también conocida como el pueblo sumo, el antropólogo Luis Hurtado de Mendoza, con base en la referencia del mayangna Baudilio Miguel, afirma que "La mayoría de las comidas que se preparaban eran masas, como el maíz, banano, pejibaye, batate, camote y con estos productos elaboraban alimentos" (2000, p. 92). Uno de los platos populares más conocidos y referenciados en la poesía nicaragüense es el 
indio viejo. Según la referencia de Baudilio Miguel esta misma comida en idioma mayangna se conoce como dikuruh o waskuruh.

En consecuencia, la base de una buena parte de los platos tradicionales de Nicaragua, según esta versión, tienen origen indígena. En palabras de este informante mayangno:

En forma general, estas comidas se preparaban triturando o moliendo con las piedras de moler en el caso del maíz; y en el caso del pejibaye se hacía masa a través de otra técnica como el recipiente de madera con la maja de madera o palo. (...) Una vez obtenida la masa, conservaban con hojas de bijagua, lo empacaban a que se pase dos días o más de fermentación y se utilizaba para preparar con carne, pescado, yemas de mangüengües o solamente la masa. Además, es utilizado como bastimento, la misma masa, pero como variaba la forma de preparación entonces se diferenciaba el gusto de una con otra. Este bastimento se conoce en lengua Mayangna como pang dam (yoltamal), tamal (tamal) y pang que es un bastimento muy común, de maíz, pejibaye, con fermentación (Hurtado de Mendoza, 2000, p. 92)

Esta base precolombina se mezcla luego con otras tradiciones formadoras de la nacionalidad nicaragüense: la hispana que representa lo mayoritario hegemónico y la afrodescendiente que se sitúa en el Caribe. Esta diferenciación estará también presente, como veremos, en la poesía. Ambos sabores regionales se enfrentan en el discurso y muestran cómo funcionan los campos nocionales de cada uno. En el caso del Centro y Pacífico, la tradición oficializa un menú que se considera como lo nicaragüense; sin embargo, el Caribe se rebela contra esta legitimidad y propone otros sabores. Detrás de este nuevo sabor hay también una visión de mundo que busca dejar clara la diferencia. Esta dinámica cultural, sin embargo, no es exclusiva de Nicaragua. Funciona de manera similar en otros países de la región centroamericana. Es importante señalar que, en el marco de las ofertas culinarias actuales, algunos restaurantes capitalinos ofrecen platos caribeños, con lo que se garantiza en cierta forma la pluralidad de esta riqueza culinaria. Pero en la poesía, este límite, en general, se mantiene como veremos más adelante en el apartado correspondiente.

\section{Funciones nocionales básicas}

Tal y como se indicó, para efectos de este trabajo, se han considerado referencias culinarias correspondientes al contexto de finales del siglo XX y principios del XXI. Sin embargo, el tema de las comidas tiene antecedentes que datan incluso del Modernismo. No es extraño, en consecuencia, que Rubén Darío resulte uno de los precursores. Un ejemplo de ello es el poema "Tríptico de Nicaragua", conformado por tres sonetos: Los bufones, Eros y Terremoto. Específicamente en el soneto Eros, al aludir a las mujeres de Chinandega, Darío la califica como una tierra: "rica en naranjas de almíbar" (Darío, 2016, p. 739). Este epíteto, más allá de la adjetivación geográfica, sugiere una correlación que aparecerá reiteradamente en la poesía nicaragüense; es decir, la vinculación entre la comida y lo erótico, pues desde el título se anuncia que este poema aborda el erotismo. De este modo, el almíbar de naranja funciona como metáfora de la exquisitez femenina presente en Chinandega.

A modo de curiosidad histórica esta acotación específica de Rubén Darío es inmediatamente retomada por otro poeta modernista, menos conocido: Juan de Dios Vanegas, quien en un poema en prosa trabaja el tema de la naranja de Chinandega y la mitifica de la siguiente manera: "La naranja ¡Qué entusiasmo! Y si es de Chinandega ¡Qué locura! Cuando Dios quiere chupar una o diez, a esa ciudad manda por ellas" (En Valle-Castillo, 1993, p. 243).

En la clasificación nocional propuesta por Roland Barthes, lo culinario, como discurso publicitario, presentaba básicamente tres posibilidades: la función rememorativa donde se hacía alusión a las virtudes históricas de la comida: su procedencia profunda, la certeza de 
una larga experiencia y una constatación de la sabiduría ancestral (Barthes, 2006, p. 218). La función antropológica, que recalca los sentimientos de superioridad o inferioridad; es decir, los rasgos hegemónicos de la comida, así como otras marcas asociadas a lo masculino o femenino y las correspondientes implicaciones de sublimación sexual. Finalmente, plantea otras nociones ambiguas, somáticas y psíquicas, principalmente en torno al concepto de salud (Barthes, 2006, p. 219).

Este modelo nocional resulta estratégico para el análisis del discurso lírico gastronómico que interesa aquí, pues también en este ámbito lo culinario incluye lo memorativo cultural y las expresiones hedonistas del cliché erótico.

En cuando a lo rememorativo cultural es posible identificar poemas que describen con detalle el menú típico nicaragüense. Se construye así una imagen de la mesa tradicional como referente de identidad y se especifica, como parte de la procedencia profunda, la especificidad geográfica, tal y como ya lo habían hecho Darío y Vanegas a propósito del almíbar de Chinandega.

Una de las descripciones más completas de este repertorio local, lo consigue el poeta Luis Rocha mediante un extenso poema titulado precisamente "Menú nica":

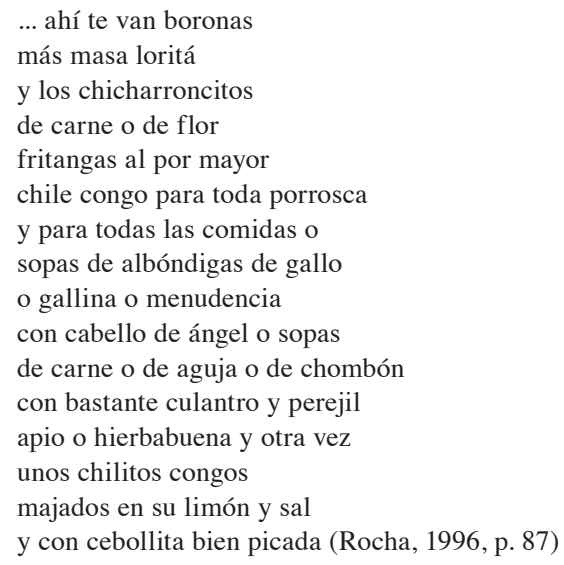

El poema abarca tres páginas y da cuenta de manera amplia de las posibilidades que tienen las comidas y bebidas nicaragüenses. Otros de los platos tradicionales mencionados son Chaguiitillo, choricitos paceños, chicharrón con yuca, venado asado a las brasas o en coyotillo, tamalito pisque, guineíto cocido, platanito asado, tortillita caliente. Nótese en esta lista la reiteración de los diminutivos como marca afectiva.

Este menú no solamente presenta marcas geográficas, sino que además ofrece referencias específicas a sitios populares donde se pueden adquirir estos platos. De este modo, el poema funciona como una suerte de guía que da cuenta del plato y de los sitios recomendados donde es posible adquirirlos.

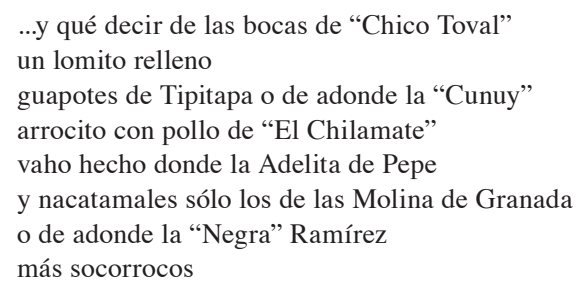




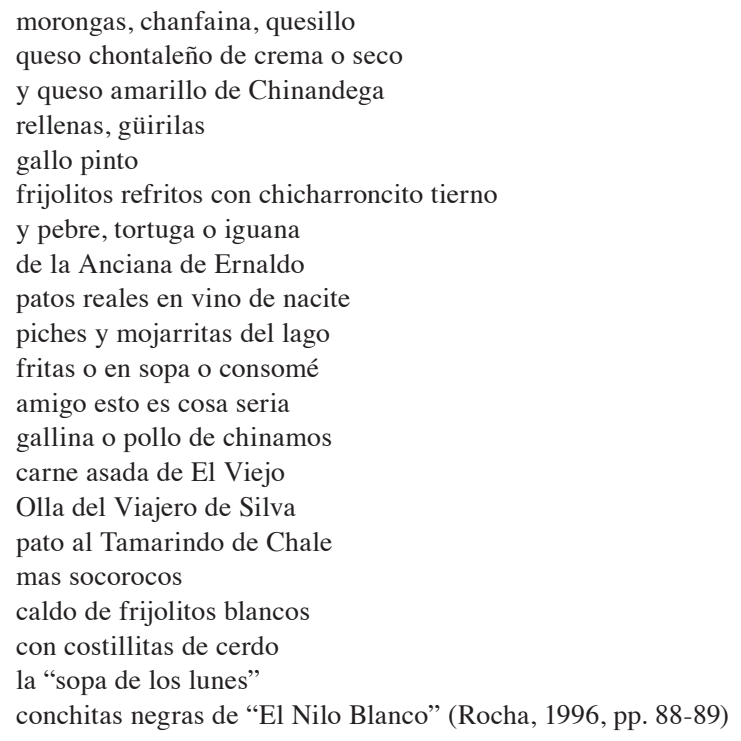

Como ya se indicó, una de las costumbres tradicionales en Nicaragua es la llamada "fritanga". Algunos de estos lugares se popularizan en torno al nombre de la persona que los atiende, especialmente mujeres. Este dato se pude constatar también en el poema de Rocha, donde aparecen las siguientes referencias: la "cunuy", la Adelita de Pepe, la "Negra" Ramírez o la Anciana de Hernaldo. El menú que presenta Rocha corresponde fundamentalmente a los platos de la oficialidad nicaragüiense, prueba de ello es que los sitios a los que se alude se ubican en Managua.

\section{Los códigos nocionales de la comida caribeña}

Por su parte, la comida que proviene de la zona caribeña cuenta también con un repertorio cuya perspectiva nocional identitaria funciona de la misma manera que la oficial, como es el caso del rondón, un plato cuya base es una sopa de pescado o mariscos, a la que se le agrega plátano verde, leche de coco, verduras, tubérculos y pimientos.

A diferencia del tratamiento que se le da en el resto del país al discurso culinario, en el caso del Caribe, como veremos, se evidencia una mayor fuerza de afirmación autónoma a través del código culinario; es decir que la identidad caribeña tiene en la comida un mayor capital simbólico que el que se le otorga en otros contextos.

Uno de los poetas del caribe nicaragüense más conocidos es Carlos Rigby, quien reivindica las raíces caribeñas de su país, entre otras estrategias, a través de la cocina local. Junto con otros poetas de la región, considera lo culinario como parte esencial del tejido de la cultura caribeña, pues la comida funciona como signo de distinción frente a la hegemonía oficial. Un ejemplo es el poema "Nicaribe soy":

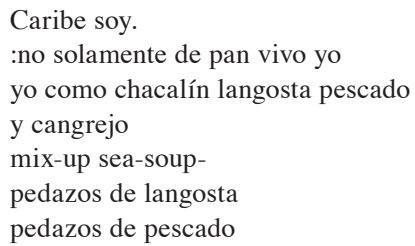


camarones y chalines enterones

y puncho de cangrejo de crab-soup (En Alemán Porras y Brooks Vargas, 2011, p. 79)

Nótese que el poema se titula "Nicaribe soy". Si bien el neologismo intenta una simbiosis cultural entre el Caribe y Nicaragua, también podría representar paradójicamente la negación: Ni Caribe soy. Esta ambigüedad está presente también en la paradoja culinaria, pues la comida finalmente es también una mezcla, un "mix-up" que se construye permanentemente entre lo posiblemente propio y lo apropiado.

Sin embargo, este poema de Rigdy desde un punto de vista ilocutivo, es decir en su propósito enunciativo, es más bien una declaración política ideológica de identificación con el triunfo de la Revolución Sandinista, pues ahora, según sus palabras, en vez de comer "mierda" los nicaragüenses pueden resolver sin injusticia el tema del hambre:

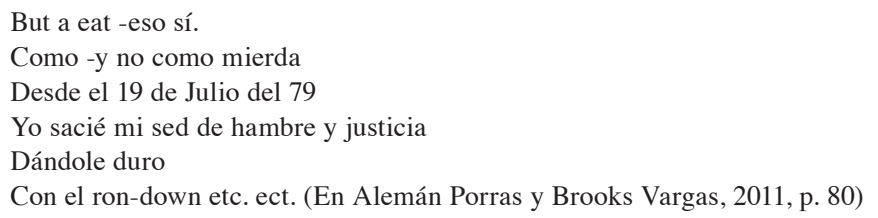

Esta noción política de la comida resulta ciertamente novedosa en esta semiosis culinaria, pues el plato típico se convierte en bandera de libertad. El nicaragüense ahora no "come mentiras", come de su propia posibilidad histórica, es decir, no necesita consumir engaños de afuera y puede entonces aferrarse a su propio sabor.

Estamos aquí frente a un ámbito nocional culinario que va más allá de la descripción folclórica de la comida típica. El plato local es una marca de libertad, de autonomía, de afirmación de lo propio frente a las amenazas de la anulación.

Una tesis similar la plantea la poeta caribeña Lesbia González en un poema titulado “Rondón es también pero que bien: ¡Autonomía!”. El poema en este caso va allá de la referencia y ofrece el detalle de la receta.

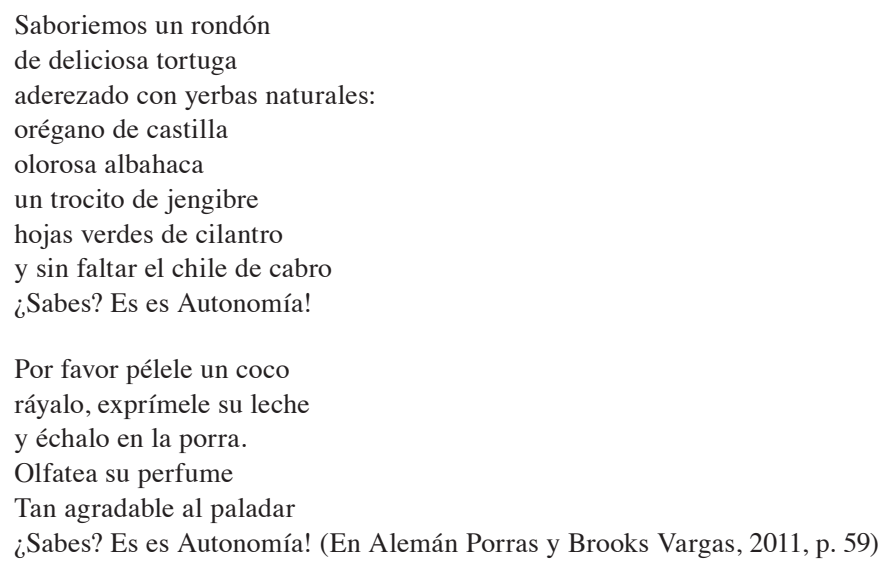

La tipología discursiva de la receta muestra en este caso el estilo propio, los ingredientes locales y la invitación a degustar el resultado. Pero el acto de preparar este rondón, va más allá de la indicación culinaria. Al igual que en la propuesta de Rigdy, la preparación de este plato implica un acto de libertad que se define como autonomía. Es decir, simbólicamente, esta es la receta o la pócima libertaria de la identidad caribeña. 
La poesía culinaria del Caribe nicaragüense, fuertemente marcada por lo nocional político, con frecuencia se desmarca del código lingüístico hegemónico y se enuncia en el inglés criollo que aún se utiliza como lengua local. Es el caso del poema "Rundown" de la poeta Lovett Martínez:

Rundown
Rundown
Rundown
Every body eat it
Every body love it
Is mama who make it
Only she could do it
She put the banana
She putt he breadfruit
She putt he coco and cassava
She dash in the plantin
She dash in the dasheen
She covers it down to let it steam down
Fish and coconut run or down
Fish and coconut run or down (En Alemán Porras y Brooks Vargas, 2011, p. 106)

Se han presentado hasta acá solamente algunos ejemplos de este código nocional político. Pero la lista es mucho más extensa y aunque se encuentran algunas nociones meramente folclóricas, la mayoría de los poemas que hacen referencia a la cocina caribeña se enuncian desde este anclaje ideológico.

\section{Otros aspectos nocionales de la cocina nicaragüense}

Por otra parte, la poesía que se produce en lo que podríamos llamar el centro hegemónico, para efectos de este mapa literario, se caracteriza por la diferenciación entre la noción folclórica y una perspectiva anunciada anteriormente: la hedonista.

En cuanto a la noción identitaria aquí también aparecen recetarios tradicionales que, en ocasiones, incluyen datos sobre los rituales de consumo. Un ejemplo es el poema "Arroz con leche" de Carola Brantone, quien plantea que este postre, que se sirve al mediodía los domingos, "Se cocina en palangana a fuego lento con cuchara de madera" (2003, p. 24), y se debe servir en platos de vidrio, color rosa viejo. Luego ofrece la receta con los detalles de la preparación:

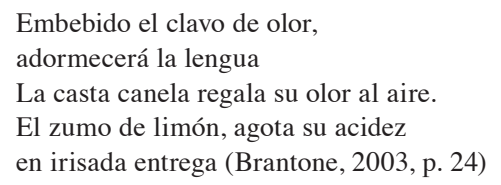

Tal como lo enuncia Roland Barthes, una de las metáforas comunes en la semiótica del discurso culinario es la asociación cliché de la comida como degustación erótica. En esta investigación se encontró que esta noción es recurrente. Por ejemplo, en el poema "Racimo de huellas" de Blanca Castellón, la tradicional pitahaya sirve como elemento de seducción en el marco de un encuentro amatorio:

... te sorprendí con las manos

llenas de pulpa de pitaya. 


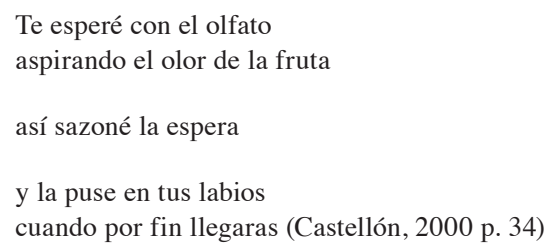

Esta misma perspectiva erótica está presente en la poética del escritor Carlos Perezalonso, quien escribe una serie de poemas dedicados a las frutas tradicionales nicaragüenses y otros productos comestibles como el ajonjolí y la yuca. En este caso se establece una correlación entre la fruta o la verdura y el cuerpo humano, más específicamente el femenino como objeto del deseo de un posible sujeto masculino. La pitahaya tiene un "tinte de labios rojos, entreabiertos, pulposos..." (2009, p. 77) y las yucas son "soterradas piernas de mujer que se desviste y muestra, /con silvestre pudor, su blancura” (2009, p. 78).

Un efecto similar aparece en la poética de Edgar Escobar Barra, quien en un poema titulado "De pesca" construye una imagen donde se mezclan la comida y la desnudez de un cuerpo que se arquea libidinoso "En el poema, en el ombligo, el jitomate. Y al compás de los labios rueda por el tobogán de tu vientre -que poco a poco se arquea- rueda una verdura roja, que va en pos del haba, leguminosa" (2003, p. 22).

Para el poeta Róger Fisher, la degustación del cuerpo deseado se consigue mediante la metáfora del catador. En este caso la correspondencia erótica se da mediante la bebida del café.

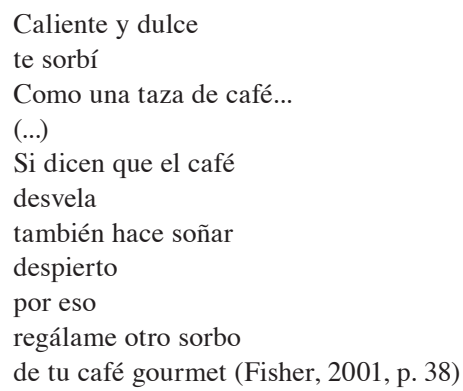

Una noción menos trabajada en la poesía culinaria de Nicaragua es la que vincula la comida con la dimensión mítica, sobre todo a propósito de las tradiciones fundacionales y teofágicas precolombinas, presentes también en el mito de la transubstanciación católica.

En el caso de la tradición ancestral mesoamericana, el maíz jugaba un papel central en este proceso nocional. Sin embargo, en la poesía nicaragüense, si bien el maíz está presente en una gran mayoría de platos, como producto primario tiene pocas referencias. Edgar Escobar Barba, aprovechándose del mito fundacional en un poema titulado "Cosecha" propone una corrección mágica entre la caricia y la emanación de maíz tierno de los poros y la ingle (2003, p. 17). Pero será Esthela Calderón la que plantea concretamente la correlación mítica entre el maíz y la carne humana en un poema titulado "Yo, maíz":

\footnotetext{
Esculpieron, pues, la primera criatura humana,

Y, con sangre de Tapir y Serpiente, amasaron su carne.

... Y así encontraron la comida

Y esta fue la que entró en la carne del hombre creado, del hombre formado; ésta fue su sangre, de ésta se hizo la sangre del hombre. Así entró el Maíz...
} 
Así todo la misma sangre, carne y alimento

Naciendo de la suma de los tiempos ciegos $(2008$, p. 9)

Este poema presenta un doble referente nocional: por un lado, explica el arquetipo fundacional con base en la intertextualidad maya presente en el Popol Vuh; y por el otro, le ofrece al enunciador una explicación corporal de su propia composición. Cuerpo y maíz, carne y comida, se fusionan en la estructura profunda de esta dimensión mítica.

\section{Conclusiones}

La poesía en Nicaragua, como herencia del magisterio dariano y la respuesta iconoclasta del vanguardismo, goza de un amplio prestigio nacional. Por esta razón, este discurso estético, resulta apropiado para dar cuenta de lo culinario como una práctica cultural asociada a la identidad local. Desde la perspectiva semiótica que se ha utilizado para este análisis, los principales campos nocionales encontrados en esta muestra de la poesía nicaragüense permiten identificar una polisemia que va desde lo meramente folclórico hasta la construcción del discurso de resistencia simbólica.

La comida, como código cultural, recoge esta mirada folclórica y la enuncia como cuadro costumbrista. Es, al menos, lo que hace el poeta Luis Rocha con su largo poema "Menú nica”. Pero, más allá de esta mera función idealista, el plato típico adquiere un sentido político que permite afirmar la identidad nacional frente a los códigos de la otredad. Las formas de la comida tradicional se presentan como prácticas de resistencia cultural en el marco de una sociedad de consumo. Es aquí donde el plato de la fritanga, y más específicamente los sabores del Caribe, asumen un rol de acceso simbólico, de la mano también con la situación socioeconómica del país.

Otro de los referentes nocionales de esta poesía es el que inaugura el propio Rubén Darío, en el poema "Tríptico de Nicaragua", donde vincula una referencia culinaria con lo erótico. La comida adquiere acá una función cliché que asocia el placer del gusto con el placer sexual. En este esquema fosilizado, las frutas son los referentes más utilizados para este ejercicio estético.

Con menos referencias, otro de los marcos nocionales de esta poesía es la que vincula el alimento con un arquetipo fundacional. En este caso, en coincidencia con los mitos precolombinos, el maíz será el referente que posibilita esta semiosis. El maíz es, además, la base alimentaria de los nicaragüenses. Tiene sentido entonces que constituya también la base simbólica para esta representación mítica.

Otra de las constataciones de este recorrido, es la diferenciación geográfica entre el modelo discursivo oficial del centro y la respuesta que ofrece, como reacción, el Caribe. La poesía que hace alusión a la gastronomía oficial tiene un enfoque mucho más folclórico, mientras que la poesía del Caribe insiste en el tema de la comida como bandera de libertad y como garantía de identidad frente a la otredad.

Desde el punto de vista del estilo, destaca el efecto conversacional que procura, en este contexto literario, una enunciación comunicativa de tipo popular. Se trata de una estética que coincide con las premisas iniciales de la poesía exteriorista, atizada por el efecto ideológico de la Revolución Sandinista, la propuesta estética de Ernesto Cardenal y la tesis de que la poesía funciona como testimonio de lo cotidiano (Cardenal, 1983, pp. 10-12). 
Estas fundamentaciones explican la enunciación que evita el "ornatus" de la retórica lírica y, temáticamente, permiten hacer referencia a los asuntos de la vida diaria. Por esta razón, el referente culinario y la alusión a los rituales de consumo cotidiano tienen en este contexto un amplio y rico menú literario.

\section{Bibliografía}

Alemán Porras, E. y Brooks Vargas, F. (2011). Bluefields en la sangre. Poesía del Caribe Sur Nicaragüense. Managua: 400 elefantes.

Barthes, R. (2006). Por una psico-sociología de la alimentación contemporánea. (L. Torres Salmerón y L. Enrique Alonso, trs.). EMPIRIA. Revista de Metodología de Ciencias Sociales, (11), 205-221.

Brantone, C. (2003). Si yo fuera una organillera. Managua: ANIDE.

Calderón, E. (2008). Soplo de corriente vital. Managua: 400 elefantes.

Cardenal, E. (1983). Talleres de poesía: socialización de los medios de producción poéticos. En Talleres de poesía. Antología. Managua: Ministerio de Cultura.

Castellón, B. (2000). Orilla opuesta. Valencia: Editorial Instituto de Estudios Modernistas.

Darío, R. (2016). Poesía completa. Madrid: Editorial Verbum.

Escobar Barba, E. (2003). Intimidaciones nocturnas. Managua: Fondo Editorial CIRA.

Fisher, R. (2001). Vivencias. Managua: SIMEN.

Hurtado de Mendoza, L. (2000). Identidad cultural Magangna en Nicaragua. Managua: Sociedad y Ambiente, consultores.

Perezalonso, C. (2009). Ocaso en el tránsito. Managua: Copy Express. S.A.

Rocha, L. (1996). La vida consciente. Managua: Nueva Nicaragua.

Tejada Gómez, A. (1974). Canto popular de las comidas. Habana: Casa de las Américas.

Valle-Castilo, J. (1993). Poetas modernistas de Nicaragua 1880-1930. Managua: Nueva Nicaragua. 